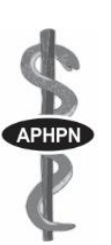

ORIGINAL ARTICLE

\title{
Medicalization of Female Genital Cutting in Sapele Local Government Area, Delta State, Nigeria: The Implication for Health Care Provision in Nigeria \\ Ikechukwu I, Isah EC, Ehinze SE
}

Department of Community Health, University of Benin, Benin City, Edo State, Nigeria

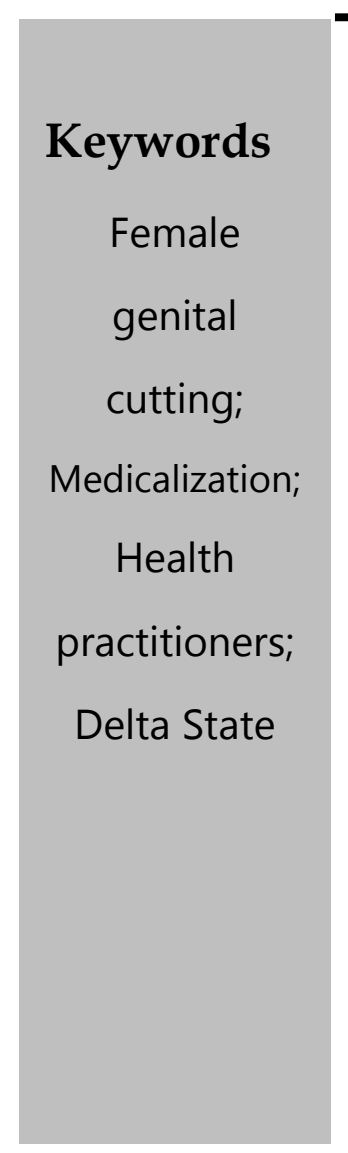

\section{INTRODUCTION}

Female genital cutting (FGC) comprises all procedures that involve partial or complete removal of the external female genitalia, or other injury to the female genital organs for non-medical reasons. ${ }^{1}$ It violates the right to physical integrity, right to health, the right

\section{ABSTRACT}

Background: Female genital cutting (FGC) affects over 200 million girls and women globally. It is inimical to health and increasingly being performed by healthcare providers. Medicalization of FGC is proposed by its proponents to reduce and prevent the incidence of its complications and though perceived to be safer, it is unethical and unjustifiable. This study assessed medicalization of FGC in Sapele Local Government Area, Delta State and made recommendations geared towards ending its practice.

Methods: A descriptive cross-sectional study was conducted among reproductive age women (15 - 44 years) selected using multi-stage sampling. Pre-tested structured questionnaire was used to obtain quantitative data from 502 women while a focus group discussion guide was used to obtain qualitative data. Data was analyzed using SPSS version 20.0 and by themes. Results were presented as tables and narratives.

Results: Prevalence of FGC was 277 (55.2\%), of which 223 (80.5\%) were medicalized. The mean age of cutting was $16.8 \pm 5.46$ years and nurses performed majority $220(79.4 \%)$ of them. Few $44(8.8 \%)$ of the respondents were aware of possible complications of FGC. Qualitative findings indicated that FGC is still being practiced with nurses being reported as major practitioners.

Conclusion: Despite concerted efforts to eliminate FGC, its practice is still propagated with increasing heath workers as practitioners. Advocacy and health education for women and girls as well as training and retraining of health care providers is imperative to check this trend.

\author{
Correspondence to: \\ Prof. Essy Isah \\ Department of Community Health, \\ University of Benin, \\ Benin City, Edo State, Nigeria
}


girls who have had it performed on them. ${ }^{2}$ Medicalization of FGC as defined by the World Health Organization refers to situations in which it is practiced by any category of health care provider, whether in a public or a private clinic, at home or elsewhere. ${ }^{3}$ Some health practitioners argue that medicalization of FGC helps to prevent the complications associated with the practice. However, FGC is neither harmless nor risk-free and there is no medical validation for its practice even when the procedure is performed in a sterile environment and by a health care provider. Healthcare practitioners have a duty of care to safeguard and protect women and young girls; but when they are seen as practitioners, social expectation that FGC should continue is strengthened.

It has been estimated that more than 200 million girls and women worldwide have been subjected to female genital cutting. ${ }^{4}$ The World Health Organization is strongly opposed to all forms of FGC and more notably, its medicalization which tend to portray the practice as risk free. An estimated 1.4 billion USD is spent yearly on the treatment of health complications of FGC in twenty-seven (27) high prevalence countries as reported by the World Health Organization. ${ }^{4}$ It has also been estimated recently by the United Nations Population Fund (UNFPA) that at least one out of five girls who have experienced FGC were cut by trained health-care providers, with some countries recording as high as three out of four cases of FGC medicalization. ${ }^{1}$
According to the 2018 Nigeria Demographic and Health Survey (NDHS), overall prevalence of FGC among women of reproductive age (15 - 49 years) is $20 \%$ wherein medical practitioners performed $7 \%$ and $9 \%$ of the procedure in girls and women, respectively. ${ }^{5} \mathrm{~A}$ previous study conducted in the study area over two decades ago showed that nurses were the major practitioners of FGC. ${ }^{6}$ According to $\mathrm{WHO}$, the practice of FGC may linger if its medicalization is not checked thus impeding the global effort to eliminate it. ${ }^{4}$ Therefore, the aim of this study was to determine the prevalence and practitioners of FGC as well as knowledge of health complications of FGC among women of reproductive age in Sapele Local Government Area (LGA), Delta State; in order to inform and develop public health policies to tackle the practice of medicalization of FGC in Nigeria, which can promote abandonment of the practice.

\section{METHODOLOGY}

The sequential explanatory mixed method descriptive cross-sectional study was conducted between November 2017 and June 2018 among women of reproductive age (15 - 44 years) in Sapele LGA, Delta State. Sapele LGA is located in the central senatorial district of Delta State, SouthSouth geopolitical zone of Nigeria, with land mass of about $450 \mathrm{~km} .{ }^{7}$ The administrative headquarters is situated at Sapele town which is linked by ferry to the road from Benin City and connects the road leading to Warri, a popular city in Delta State. The 
predominant ethnic group is Okpe although other ethnic groups also reside in the study area. Sapele Local Government Area is an oil producing area with the presence of Seplat Petroleum Development Company and has a flour-milling plant as well. Sapele was known for its foremost timber production in Africa and the city was also famous for the rubber plantations in the locality. Sapele LGA has an estimated population of $249,470^{8}$ as at 2017 projected from the 2006 National Population Commission census figures.

The study population comprised of women of reproductive age group (15 - 44 years) who accounted for $50.6 \%$ of the population of Sapele LGA, of which adolescents comprise an estimated $48.2 \%$ of the female population. ${ }^{8}$ The Cochran formula ${ }^{9} \mathrm{n}=$ $\mathrm{Z}^{2} \mathrm{pq} / \mathrm{d}^{2}$ was used to estimate sample size using 95\% confidence level, 5\% degree of precision, a design effect of 1.5 and $66 \%$ prevalence (of a previous study on FGC conducted in a general hospital at Oleh, Delta State $\left.{ }^{10}\right)$. Adjustment was made for non-response rate by adding $10 \%(51)$ to the calculated sample size yielding a minimum sample size of 568 .

A multi-stage sampling method was employed for the study. The existing Independent National Electoral Commission (INEC) grouping of wards in Sapele LGA comprising of eleven wards was used as sampling frame. ${ }^{11}$ Five wards were selected from the eleven wards by balloting, after which two communities per ward were selected from the five wards by balloting.
The list of streets in the selected communities was obtained from Sapele LGA administrative headquarters and a total of forty-seven residential streets were collated. Twenty-four streets (50\%) were selected from the forty-seven residential streets by the use of computer-generated random numbers. Study participants were recruited from house to house and data was collected from all the women that met the selection criteria in the selected streets until sample size was achieved. Any house with a woman that met the selection criteria who was not present at the time of data collection was skipped and the next house was visited and data collected.

Data was collected using intervieweradministered structured questionnaire that had been pretested in Mosogar community, a similar community in Ethiope-West LGA using 59 respondents. The study questionnaires were administered by four indigenous female diploma graduates research assistants who were given two days intensive training on data collection. The qualitative study was conducted utilizing focus group discussions (FGDs) which were conducted in three known major communities in Sapele LGA amongst twenty-four participants (eight participants per group) by the principal investigator and two research assistants. Homogenous purposive sampling technique was employed to select participants for focus group discussion and each session lasted an average of 50 minutes. The groups for FGDs were made homogeneous in terms of educational attainment and age. The 
locations used were easily accessible, comfortable and the environment was not noisy. Verbal informed consent was obtained from the respondents before the discussion began and a semi-structured questions guide was used to lead the discussion. A brief introduction of the topic was given and participants were encouraged to speak freely and assured of anonymity of information. The term female circumcision was employed for the focus group interview and responses were documented by the two research assistants who were the recorders. Audio recording was carried out and written notes were taken to provide context and clarification.

The quantitative data were checked for completeness, coded and entered into computer using Statistical package for scientific solution (SPSS) version 20.0. Frequencies and proportions were used to summarize descriptive statistics of the data. The qualitative data were translated verbatim by the researcher by replaying the recorded interview. After the transcription, the diverse ideas in the transcript that were recurring were identified and grouped into themes. The selected themes were reviewed and the result was presented in narratives.

Institutional approval for this study was obtained from the University of Benin (Ref: CMS/REC/2018/003) and permission was sought from community leaders as well before conducting the study. Verbal informed consent was also sought from nonliterate respondents, while the literate respondents signed an informed consent form before the interviews. Participants were informed that there were no risks to their participation which was voluntary, and they could withdraw their participation anytime during the interview. In addition, serial numbers were used instead of names for the identification of the respondents to ensure privacy and confidentiality of information.

\section{RESULTS}

A total of 568 women of reproductive age participated in the quantitative study. However, only 502 questionnaires were correctly filled yielding a response rate of $88.4 \%$. The socio-demographic characteristics of the respondents are shown on Table 1. The age range was $15-44$ years (Mean $\pm \mathrm{SD}=31.9 \pm 6.32$ ) with a slightly higher proportion, $274(54.6 \%)$ in the $25-34$ age bracket. Majority were married 454 (90.4\%), Christians 482 (96\%) and 262 (52.2\%) had secondary level of education. The prevalence of FGC was 277 (55.2\%) with 125 (45.1\%) disclosing that they were cut within the adolescent (15 - 19) age group; 93 (33.6\%) at 20 and above age group while the mean age at cutting was $16.8 \pm 5.46$ years. The practitioners of FGC were mainly nurses $220(79.4 \%)$, followed by the traditional circumcisers $20(7.2 \%)$ while $25(9.0 \%)$ of those cut did not know the practitioners. Majority 237 (85.5\%) of the respondents reported they had their clitoris cut (type 1 FGC) while 40 (14.5\%) had no idea which type they underwent. (Table 2)

Table 3 shows the awareness of health complications associated with FGC among the respondents. 
Table 1: Socio-demographic characteristics of the respondents

\begin{tabular}{|c|c|c|}
\hline Variable & $\begin{array}{l}\text { Frequency } \\
(\mathrm{n}=502)\end{array}$ & Percent \\
\hline \multicolumn{3}{|c|}{ Age group (years) } \\
\hline $15-24$ & 55 & 10.9 \\
\hline $25-34$ & 274 & 54.6 \\
\hline $35-44$ & 173 & 34.5 \\
\hline \multicolumn{3}{|l|}{ Marital status } \\
\hline Never married & 48 & 9.6 \\
\hline Married & 454 & 90.4 \\
\hline \multicolumn{3}{|l|}{ Ethnicity } \\
\hline Okpe & 208 & 41.4 \\
\hline Urhobo & 174 & 34.7 \\
\hline Itsekiri & 22 & 4.4 \\
\hline Ijaw & 30 & 6.0 \\
\hline Bini & 39 & 7.8 \\
\hline Yoruba & 15 & 2.9 \\
\hline Others* & 14 & 2.8 \\
\hline \multicolumn{3}{|l|}{$\begin{array}{l}\text { Level of } \\
\text { education }\end{array}$} \\
\hline None & 32 & 6.4 \\
\hline Primary & 33 & 6.6 \\
\hline Secondary & 262 & 52.2 \\
\hline Tertiary & 175 & 34.8 \\
\hline \multicolumn{3}{|l|}{ Occupation } \\
\hline Business & 290 & 57.8 \\
\hline Civil servant & 99 & 19.7 \\
\hline Artisans & 62 & 12.3 \\
\hline Farming & 51 & 10.2 \\
\hline \multicolumn{3}{|l|}{ Religion } \\
\hline Christianity & 482 & 96.0 \\
\hline Islam & 13 & 2.6 \\
\hline $\begin{array}{l}\text { African Traditional } \\
\text { Religion }\end{array}$ & 7 & 1.4 \\
\hline
\end{tabular}

A high proportion 458 (91.2\%) were not aware of any health problems associated with FGC. A little above half 23 (52.3\%) of those who were aware of complications of FGC mentioned keloid formation while 12 $(27.3 \%)$ mentioned prolonged bleeding. A greater proportion 263 (94.9\%) of those cut claimed that they experienced no complications after the cutting while 14
(5.1\%) experienced poor healing of their wounds.

The FGD findings are presented under three themes: Opinion on practice of FGC, practitioners of FGC and awareness of complication resulting from FGC.

\section{Opinion on practice of FGC}

FGC was still practiced in Sapele LGA though it has become less rampant. It was generally opined by the participants that FGC was pervasive and performed on most women at some point in their life. It was the known norm and not usually questioned. It is notable for its cultural significance as a premarital ritual aimed at curbing promiscuity in women and girls. However, the rate at which the practice is done is declining.

"Female circumcision is still practiced in this community. Before now, when a girl is not circumcised, her mates mock her because she has not been circumcised." (39 years old participant - FGD 3)

"Female circumcision is practiced in this community. It reigned very well in my time compared to now, but circumcision of girls has not stopped, it is still done in this community." (33 years old participant - FGD 2).

The practice has been promulgated for a long time and is passed down from one generation to the next. 
Table 2: Prevalence of female genital cutting among respondents

\begin{tabular}{|c|c|c|}
\hline Variable & Frequency & Percent \\
\hline \multicolumn{3}{|l|}{ Circumcision status ( $n=502)$} \\
\hline Circumcised & 277 & 55.2 \\
\hline Not circumcised & 200 & 39.8 \\
\hline Don’t know & 25 & 5.0 \\
\hline \multicolumn{3}{|l|}{ Type of circumcision $(n=277)$} \\
\hline Clitoridal (Type 1) & 237 & 85.5 \\
\hline Don’t know & 40 & 15.5 \\
\hline \multicolumn{3}{|l|}{ Age at circumcision $(n=277)$} \\
\hline$<5$ years & 21 & 7.6 \\
\hline $5-9$ years & 3 & 1.1 \\
\hline $10-14$ years & 35 & 12.6 \\
\hline $15-19$ years & 125 & 45.1 \\
\hline$\geq 20$ years & 93 & 33.6 \\
\hline \multicolumn{3}{|c|}{ Mean age at circumcision $=16.8 \pm 5.46$ years } \\
\hline \multicolumn{3}{|l|}{ Complication experienced $(n=277)$} \\
\hline Wound that did not heal properly & 14 & 5.1 \\
\hline None & 263 & 94.9 \\
\hline \multicolumn{3}{|l|}{ Practitioners of FGC $(n=277)$} \\
\hline Nurses & 220 & 79.4 \\
\hline Traditional circumcisers & 20 & 7.2 \\
\hline Traditional birth attendants & 9 & 3.3 \\
\hline Doctors & 3 & 1.1 \\
\hline Don't know & 25 & 9.0 \\
\hline
\end{tabular}

Table 3: Awareness of health complications associated with FGC

\begin{tabular}{lcc}
\hline Variable & Frequency & Percent \\
\hline Aware of complications of FGC (n = 502) & 44 & 8.8 \\
Aware & 458 & 91.2 \\
Not aware & & \\
Type of complication known (n =44) & 12 & 27.3 \\
Prolonged bleeding & 23 & 52.3 \\
Formation of keloid scar & 7 & 15.9 \\
Swelling in the genital area & 2 & 4.5 \\
Complication during childbirth & & \\
\hline
\end{tabular}

"Female circumcision is a tradition handed over to us by our ancestors." (44 years old Participant - FGD 1).

However, it was also revealed that the decline in practice is associated with refusal by some of the girls in the community to undergo FGC even when their mothers still want the practice promulgated.

"We still want to practice it, but some of the girls now refuse. When you ask them the reason for their refusal, they say the uncircumcised is better." (40 years old participant - FGD 2)

"Some of the girls now say no, we could not say no to our mother when it was time for circumcision. Modern life is changing the practice.” (37 years old Participant - FGD 1)

\section{Practitioners of FGC}

It was reported that nurses were the major practitioners of female genital cutting in Sapele LGA. The cutting can be done at the health facility or at home at an agreed fee. 
Prior to cutting, local anesthesia is administered to numb pain during the procedure. Traditional birth attendants or traditional circumcisers were no longer in vogue as practitioners of FGC as it was acclaimed to be a native method practiced many years ago.

"Nurses are the ones that help to circumcise girls. A certain nurse told me the women always come to the health facility and insist circumcision is their culture. She said she collects the money, nicks the clitoris but she doesn't cut." (35 years old participant - FGD 2)

"In my case, it was a nurse that instigated my circumcision. As Itsekiris, we don't circumcise women, but I'm married to an Okpe man. When I was pregnant for my first child, my sister in-law who is a nurse told my husband it was time for me to be circumcised. My husband informed me and I agreed, I told her I will not come to her clinic because it was far from our location. She came over to us and circumcised me, I was about six months old pregnant at that time." (43 years old circumcised participant - FGD 3)

\section{Awareness of complications resulting from FGC}

Most circumcised participants reported they did not experience complications after undergoing FGC, but were aware complications occurred in time past when the procedure was carried out by traditional circumcisers and traditional birth attendants. They opined that that circumcision carried out by nurses was devoid of pain and free from health complications. Some of the participants remarked as follows:

"I don't know of any. I didn't even feel pain when it was done. The nurse injected me and Ifelt nothing when she did the cutting. It was when I was about to urinate I felt pain, and that did not last more than two weeks." (35 years old circumcised participant - FGD 2)

"There is no problem, I did not experience any. Those who have complaints were as a result of lack of maintenance. They did not use hot water to press the area after the circumcision." (33 years old circumcised participant - FGD 2)

"Circumcision does not cause any health problem. It is those that witchcraft affected that have problems, female circumcision is good, I want you to tell people about it." (44 years old circumcised participant - FGD 2).

The immediate physical complication aware of was prolonged bleeding; which was also attributed to traditional methods of cutting.

"The bleeding that used to happen because of circumcision is if they cut it too much, but they know the method now, no problem with circumcision." (36 years old participant FGD 2).

"It was when circumcision was done raw (i.e. native method) that some people experienced problem like bleeding. That one is very painful; they sit on your chest and tie you down." (29 years old participant - FGD 3).

However, majority of the women who experienced female genital cutting reported 
psychosexual complication as an aftermath of female genital cutting. They reported little or no urge for sexual intercourse after undergoing female genital cutting. Thus, this psychosexual effect of FGC was the basis of their opinion for the discontinuation of female genital cutting.

"After I married, I just feel like a dead wood in the house, I don't feel any urge for sex." (44 years old circumcised participant - FGD $3)$.

In my case, I was circumcised twice because the relatives I lived with did not believe me when I told them I was circumcised before. Maybe, that was what killed the entire urge to have sex. I don't feel any urge to have sex. My husband is understanding, else, I think by now, the marriage would have been over." (30 years circumcised participant - FGD 1).

"Female circumcision kills urge for sex, that is why it is commonly said Okpe women are not good in bed." (36 years old circumcised participant - FGD 2).

\section{DISCUSSION}

The high prevalence of medicalization of FGC found in this study with nurses as the majority of practitioners indicate that the use of health workers as practitioners of FGC may be on the increase. A previous study conducted among Okpe (Sapele) people over two decades ago (1994) reported that half of the FGC carried out were done by nurses. ${ }^{6}$ This is suggestive of the fact that medicalization of FGC is not a new trend, but has persisted in this study area for such a long time. Medicalized cutting is very popular in three countries namely; Egypt, Sudan and Nigeria where $93 \%$ of women who report having been cut by a health care practitioner reside. ${ }^{12}$ Services of health professionals as practitioners of FGC are reportedly in high demand since it is assumed that they use sterile instruments and administer local anesthetic that reduces pain in the vulva, allowing for more controlled cutting ${ }^{13,14}$ and for its preference over more radical forms of FGC. ${ }^{14}$

However, trained health professionals who perform FGC are causing harm ${ }^{15}$ and thus violating the fundamental medical ethics to "do no harm." Studies in Nigeria and Sudan $13,16,17$ have also shown that some of the medical practitioners of FGC claim that they are fulfilling the cultural demands of the community they serve and some even share the same beliefs as community members on perceived benefits of FGC. Regardless of any justification for medicalization, the overall goal to end FGC will not be achieved if medicalization persists.

Only a few $(8.8 \%)$ of the respondents in this study were aware of health complications associated with FGC, a figure that is much lower than the $42.6 \%$ obtained in another study in two rural communities in Nigeria. ${ }^{18}$ The low level of awareness of health risks from FGC in this study may be ascribed to the medicalization of the process and ignorance of its long term consequences. Families and individuals often erroneously believe FGC is safe if carried out by a health care provider. This is reiterated in the FGD 
groups where participants reported that complications were associated with FGC only when it was done by traditional circumcisers and that the ones done by nurses are devoid of pain and health complications. In the same vein, some health practitioners advocate medicalization as a harm-reduction strategy ${ }^{14}$ even when there is no evidence that medicalization reduces the long-term complications associated with it. ${ }^{19}$

Some respondents in the qualitative study attributed complications from FGC to witchcraft attacks and not to the circumcision, an assertion which compares well with those from another study in Edo State, Nigeria where the respondents attributed complications from FGC to 'unseen forces' as they argued that the traditional circumcisers were trusted hands who had circumcised many females in their communities without any complications. ${ }^{20}$ People must be enlightened on the adverse consequences of FGC. When adequate information about the health risks of FGC is provided; people may develop positive attitude towards the practice of FGC. It is believed that an increased awareness and knowledge of the adverse health outcomes can encourage decisive thinking leading to the abandonment of the practice of FGC. 21

It is also imperative to leverage on involvement of health care workers to promote abandonment of FGC. They must refrain from the practice and advocate against it in all health settings where women present. As critical stakeholders, beyond just identifying and caring for complications of FGC, health practitioners should be involved in the campaign against FGC. However, to be effective, the information has to be communicated in a way that is culturally sensitive and adaptable to the community need. Health education on FGC should also be incorporated into antenatal and postnatal services.

Eliminating FGC is one of the essential steps in realizing the Sustainable Development Goal (SDG) 5, in particular target 3 which seeks to eliminate all harmful practices such as child, early and forced marriage and female genital mutilation. It has also been highlighted as a vital way to achieving gender equity and by extension all the other SDGs. ${ }^{22}$ This is particularly important for Nigeria and the rest of subSaharan Africa thus keeping us on the right path towards achieving the SDGs.

Limitations of the study: The prevalence of FGC in this study was based on selfreported data. Physical examination of the genitals was not done to verify the reports. However, effort was made to encourage respondents to speak freely and provide honest answers, as information supplied will be strictly confidential and no penalty/punishment will accrue for the answers they give, so as to minimize bias. Female research assistants were purposefully selected to aid ease of communication as the women may likely express themselves freely with their fellow female folks considering the sensitive nature of the topic. 
Conclusion and Recommendations: It is evident that medicalization promotes the perpetuity of FGC practice in Sapele LGA of Delta State, Nigeria. There is dire need for intervention to limit medicalization in Sapele LGA as medicalization impedes progress of effort to abandon the practice. Health care providers especially nurses should be trained and retrained by medical and social experts on the need to educate the general populace and especially women when they present at the clinics for FGC in a culturally sensitive manner for a positive behavioral change. They must be adequately prepared to educate the women when they insist female circumcision is part of their culture. This training should be integrated in to the curriculum for health care practitioners to prepare them adequately for the task of promoting the abandonment of FGC. It is important that health practitioners worldwide are acquainted with the damage FGC causes to the health of the circumcised in the short and long term. Policy makers will be instrumental in developing and implementing health-care policies targeted at ensuring standard compliance to medical ethics by health practitioners. Health education on FGC and its adverse effect for women and girls is also imperative to curb the practice. Women and girls should be enlightened about complications on FGC which is not limited to immediate complications circumvented by medicalization. They should be acquainted with its long term consequences such as its psychosexual effects revealed in this study.
Acknowledgement: We acknowledge the Sapele Local Government Area authority and the indigenous research assistants for their supportive roles in carrying out this research.

Conflict of interest: The authors declare no conflict of interest.

Authors' contributions: II and IEC conceived the study and contributed to the study design; II contributed to data collection, data analysis and interpretation. IEC, II and ESE contributed substantially to drafting the manuscript, IEC provided critical revision of the manuscript and supervised the entire research work. All Authors contributed to the discussion and final version to be published.

\section{REFERENCES}

1. United Nations Population Fund. Female genital mutilation: Frequently asked questions. [Cited August 10, 2019]. Available from https://www.unfpa.org/resources/fema le-genital-mutilation-fgm-frequentlyasked-questions.

2. Serour GI. Medicalization of female genital mutilation/cutting. Afr J Urol. 2013; 19(3): 145-149.

3. World Health Organization. Global strategy to stop health-care providers from performing female genital mutilation. [Cited August 10, 2019]. Available from https://www.who.int/reproductivehealt h/publications/fgm/rhr_10_9/en/.

4. World Health Organization. Female genital mutilation. Key facts. Feb, 2020. [Cited July 19, 2020]. Available from: https://www.who.int/news-room/factsheets/detail/female-genital-mutilation.

5. National Population Commission (NPC) [Nigeria] and ICF. 2019. Nigeria Demographic and Health Survey 2018.Abuja, Nigeria, and Rockville, Maryland, USA: NPC and ICF., Abuja. pp 470. [Cited July 19, 2020]. Available from:

https://dhsprogram.com/pubs/pdf/fr2 93/fr293.pdf]. 
6. Owumi BE. The persistence of female circumcision in Nigeria: A case study of the Okpe people of Delta State. Afr J Psy Study of Soc issues. 1994; 1(2): 297-308.

7. Encyclopaedia Britannica. Sapele. [Cited January 10, 2017). Available from: https://www.britannica.com/place/sap ele. 2009.

8. National Population Commission. Population distribution by age and sex: Priority table iv. [Cited June 21, 2017]. Available from: http://www.population.gov.ng/index.ph $\mathrm{p} /$ newsletter/141-populationdistribution-by-age-and-sex-2006census-priority-tables-vol-4.P.97.

9. Cochran WG. Sampling techniques. 3rd edition. New York: John Wiley \& Sons; 1977.

10. Awusi VO. Tradition versus female circumcision: A study of female circumcision among the Isoko tribe of Delta State of Nigeria. Benin J Postgrad Med. 2009; 11(1): 1-7.

11. Independent National Electoral Commission. Sapele Local Government Area wards. [Cited January 10, 2017]. Available from:

http://www.inecnigeria.org/?age_id=20.

12. Shell-Duncan B, Zhuzhi M, Njue C. The medicalization of female genital mutilation/cutting: what do the data reveal? Evidence to end fgm/c: research to Help Women Thrive. 2017; New York: Population Council. [Cited July 30, 2018]. Available from http://www.popcouncil.org/uploads/pd fs/2017 RH_M edicalizationFGMC.pdf.

13. Obianwu O, Adetunji A, Dirisu O. Understanding medicalization of female genital mutilation/cutting (FGM/C): A qualitative study of parents and health workers in Nigeria. Evidence to end FGM/C: Research to Help Women Thrive. 2018. New York: Population Council.

14. Pearce AJ, Bewley S. Medicalization of female genital mutilation: Harm reduction or unethical. Obstet Gynaecol Reprod Med. 2013: 24(1): 29-30.

15. World Health Organization. Working to end myths and misconceptions about female genital mutilation. Feb, 2018.
[Cited August 10, 2019]. Available from: https://www.who.int/reproductive health/topics/fgm/zero-tolerancefgm/en/.https://www.who.int/reprodu ctive health/topics/fgm/zero-tolerance$\mathrm{fgm} / \mathrm{en} /$.

16. Leye E, Van EekertV, Shamu S, Esho T, Barret HR. Debating medicalization of Female Genital Mutilation/Cutting (FGM/C): learning from (policy) experiences across countries. Reprod Health 2019; 16(1): 158.

17. Bukuluki P, Wisal A, Al Gasseer NH, Dalya E. Drivers for FGM medicalization among community midwives in River Nile and Northern State, Sudan. Reproductive Health. 2017; 14(2): 6 .

18. Okhiai O, Idonijie OB, Asika EC. Awareness of health risks of female genital mutilation among women of child bearing age in two rural communities in Nigeria. Asian J Med Sci 2011; 3(6): 223227.

19. World Health Organization, Department of Reproductive Health and Research. Eliminating female genital mutilation: An interagency statement. OHCRH, UNSIDS, UNDP, UNECA, UNESCO, UNFPA, UNHCR, UNICEF, UNIFEM, WHO, 2008. [Cited July, 30, 2018]. Available from: https://www.who.int/ reproductivehealth/publicationsfgm /9789241596442/en/

20. Osifo DO, Evbuomwan I. Female genital mutilation among Edo people: The complications and pattern of presentation at a Paediatric Surgery Unit in Benin City. Afr J Reprod Health. 2009; 13(1): 17-25.

21. Johansen REB, Diop NJ, Laverack G, Leye E. What works and what does not: A discussion of popular approaches for the abandonment of female genital mutilation. Obstet Gynecol Int. 2013; 2013: 1-6.

22. United Nations Children's Fund. SDG briefing note 10: Goal 5- Achieve gender equality and empower all girls and women. New York. [Cited August 10, 2020]. Available from: https://data.unicef.org 